\title{
Antitumor activity of enzastaurin (LY317615.HCI) against human cancer cell lines and freshly explanted tumors investigated in in-vitro soft-agar cloning experiments
}

Axel-Rainer Hanauske - Olaf Oberschmidt •

Hartmut Hanauske-Abel • Michael M. Lahn •

Ulrike Eismann

Published online: 18 April 2007

(C) Springer Science + Business Media, LLC 2007

In the online and print version of the original article, there was a typographical error in the title. The correct title is indicated above.

The online version of the original article can be found at http://dx.doi. org/10.1007/s10637-007-9038-7.

A.-R. Hanauske $(\bowtie) \cdot$ O. Oberschmidt $\cdot$ U. Eismann

Asklepios Klinik St. Georg, Lohmühlenstr. 5,

20099 Hamburg, Germany

e-mail: tian64@gmx.de

A.-R. Hanauske

e-mail: hanauske.ind-synergen@t-online.de

H. Hanauske-Abel

UMDNJ-New Jersey Medical School, Newark, NJ 07103-2714, USA

M. M. Lahn

Eli Lilly \& Company, Indianapolis, IN 46285, USA 